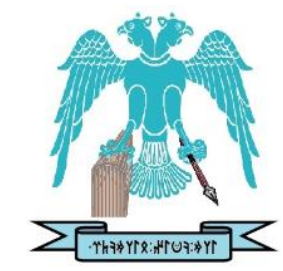

JOURNAL OF ENERGY SYSTEMS

$2021,5(3)$

\title{
Techno-economic analysis of a transmission line between an island grid and a mainland grid
}

Barış Çağnı Dinç

Middle East Technical University, Northern Cyprus Campus, Kalkanli, Guzelyurt via Mersin 10, 99738 ,

Turkey, baris.dinc@metu.edu.tr

ASELSAN, Technology and Strategy Vice Presidency, Turkey, bcdinc@aselsan.com.tr

Murat Fahrioğlu

Middle East Technical University, Northern Cyprus Campus, Kalkanli, Guzelyurt via Mersin 10, 99738, Turkey, fmurat@metu.edu.tr

Canraş Batunlu

Middle East Technical University, Northern Cyprus Campus, Kalkanli, Guzelyurt via Mersin 10, 99738,

Turkey, cbatunlu@metu.edu.tr

$\begin{array}{rr}\text { Submitted: } & 10.02 .2020 \\ \text { Accepted: } & 18.08 .2021\end{array}$

Published: $\quad 30.09 .2021$

\begin{abstract}
Islands are commonly isolated electricity systems that rely heavily on imported fossil fuels. Interconnection with a mainland power system is a solution to offset the exposure to volatile fuel prices and increase the stability of the island grid. This paper presents and discusses the main results of a case study aiming to see the economic effects of a 200 MW HVDC connection between an island grid and a mainland grid. The purpose was to see how much of the island's oil price scenarios can be overcome with this new interconnector. For this research, North Cyprus grid was modeled in MATPOWER software to do optimal power flow analysis. The results are used to compare fuel-based generation costs to importing electricity from the mainland. The analysis shows that this interconnector decreases the island's generation costs by $28 \%$ to $78 \%$, and with the possible renewable installations, this reduction can be increased further.
\end{abstract}

Keywords: Island grid, HVDC, Techno-economic analysis, Transmission line

Cite this paper as:

Dinç, B.Ç., Fahrioğlu, M., Batunlu, C., Techno-economic analysis of a transmission line between an island grid and a mainland grid, Journal of Energy Systems 2021, 5(3), 186198, DOI: $10.30521 /$ jes. 838784

(c) 2021 Published by peer-reviewed open access scientific journal, JES at DergiPark (https://dergipark.org.tr/en/pub/jes)

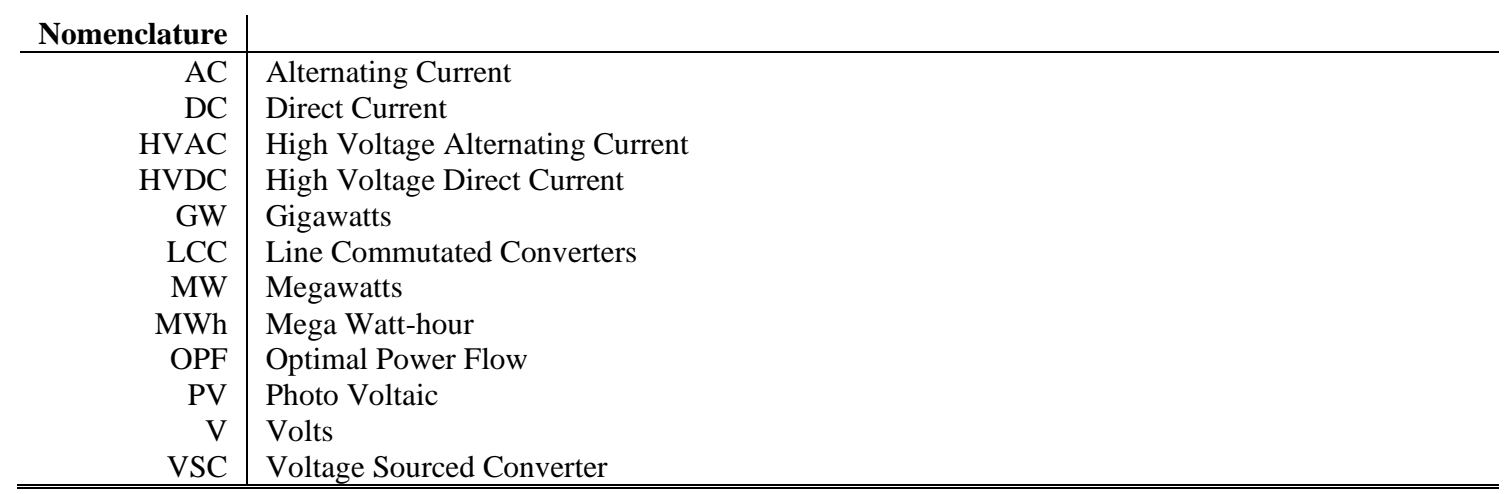




\section{INTRODUCTION}

Island power systems face many problems due to insecure sources and expensive fuels. Island grids typically have high electricity rates and face stability problems. As they are small by nature, island grids also limit renewables integration into the generation mix. Among different solutions, interconnection systems are good options for islands with a feasible distance to the mainland. Likewise, development in both cable technology and Alternating Current- Direct Current (AC-DC) conversions created feasible transmission line solutions. However, projects employing these solutions are high-cost.

Cyprus is one of the biggest islands in the Mediterranean. The island is split into two parts, North Cyprus (population near 370 thousand) and the Republic of Cyprus. The focus of this study is the North Cyprus power grid, where $90 \%$ of its energy needs depend on imported fossil fuel [1], causing an energy insecurity issue.

In terms of energy, the most characteristic feature of North Cyprus is its solar energy potentialmeasuring between 1900 to $2500 \mathrm{kWh}$ per square meter [2] during the year- is Europe's best. There have been many applications employed and investments made on the island to use this potential. Civil and governmental projects have played a significant role in establishing solar energy systems. There has been a significant amount of installations made throughout the island. However, problems occurred due to the stability problems in the grid caused by the excess in the solar installations [3]. In this situation, solar energy usage can be increased with projects and solutions that will not cause any problems. Examples of these solutions can be listed as energy storage systems, concentrated solar thermal power plants, and an interconnector to a much bigger grid. Among these solutions, the most significant benefit, in the long run, can be achieved by establishing an interconnection to the mainland. High Voltage Alternating Current (HVAC) or High Voltage Direct Current (HVDC) connections are used for these kinds of connections.

Today, HVDC transmission lines are used on many occasions, like power delivery from wind turbines or the connection of different grid systems. These connections also help usable renewable potential because renewable energy generation on one network is limited and requires a robust electrical grid due to the nature of renewable energy. For example, Denmark has achieved extreme wind power thanks to its connection with Germany and other countries [4].

There is considerable research on the technology and economic analysis of transmission lines between the island networks and mainland grids. One study [5] focused on long-term submarine transmission between the Greek islands and the mainland uses PLEXOS software. The results show that generation costs are drastically reduced from 200-600 €/MWh to 20-100 $€ / \mathrm{MWh}$, and with an increase in renewable energy generation, carbon emissions are reduced up to $60 \%$. Similar research focuses on the interconnection between Greek islands and the mainland and the effect of interconnection on renewables. Study shows that Greece can achieve \%56 renewable penetration on islands with interconnection planning. [6] Another study focused on Crete [7], with bipolar voltage source converter (VSC) based HVDC connection between the island and mainland grids. The study estimated an increase in renewables by $22 \%$ to $71 \%$ for wind and $5.5 \%$ to $11.5 \%$ for PV systems, which decreased annual costs for HVDC links, but no general generation costs were estimated. A similar study [8] focuses on Aegean islands with a similar approach, where island and mainland connection is assumed to be a submarine HVDC cable. The results show a $20 \%$ cost deduction and twice as wind power usage through the islands. Another study focuses frequency improvement of Sardinia Island grid under high penetration of renewable with HVDC transmission and achieved 0.47 $\mathrm{Hz}$ improvement.[9] Finally, another study was done on Cycladic Islands [10], where the authors examined different submarine cable scenarios and estimated improved energy quality and fewer environmental impacts than the diesel generation implementation. 
This study examines an HVDC interconnection cable from North Cyprus to Turkey. It explains the current situation for the two countries and current HVDC technologies. Fundamental economic analysis is done with the Optimal Power Flow method. MATPOWER [11] is used for optimal power flow calculations, and the North Cyprus grid is modeled on the same software.

\section{CURRENT ENERGY SITUATION OF TURKEY AND NORTH CYPRUS}

With an increasing population, energy demand increases drastically. This population increase creates demand problems for the countries. To satisfy this, governments make investments for new generation methods, some transmission systems, and renewables. In Turkey's case, energy demand growth has been $5.5 \%$ since 2002 . As a result, Turkey reached $90.4 \mathrm{GW}$ of installed capacity as of July 2019, a three-fold increase in 15 years. This installed capacity makes Turkey's network second most prominent in Europe after Germany. North Cyprus, an island country, has a small electricity network compared to Turkey, which has 404 MW of installed capacity. Highly synchronized generation capacity makes Turkey an excellent candidate for establishing an electrical connection between the two countries. Also, Turkey has an active electricity market with many players, which could be a start point to create an electricity market in North Cyprus.

North Cyprus uses mainly diesel generators and steam turbines to produce energy. Besides these, connection with South Cyprus and renewables are used for more electricity. North Cyprus currently has 16 Diesel generators. Each has 17.5 MW active power capacity, $120 \mathrm{MW}$ of steam turbines, and a 1.27 MW of solar energy system, making nearly $405 \mathrm{MW}$ of installed capacity overall [12].

Because of low synchronous generation capacity, North Cyprus needs to deal with frequency problems, blackouts, and low renewable installation limitations. North Cyprus connected its grid to South Cyprus to compensate for these problems, so there is one united network. The current transmission network of the island consists of $132 \mathrm{kV}$ and $66 \mathrm{kV}$ lines, and distribution is done on $11 \mathrm{kV}$ and $22 \mathrm{kV}$ levels. The island network provided by Kıbrıs Türk Elektrik Kurumu (KIB-TEK) [1] can be seen in Fig. 1.

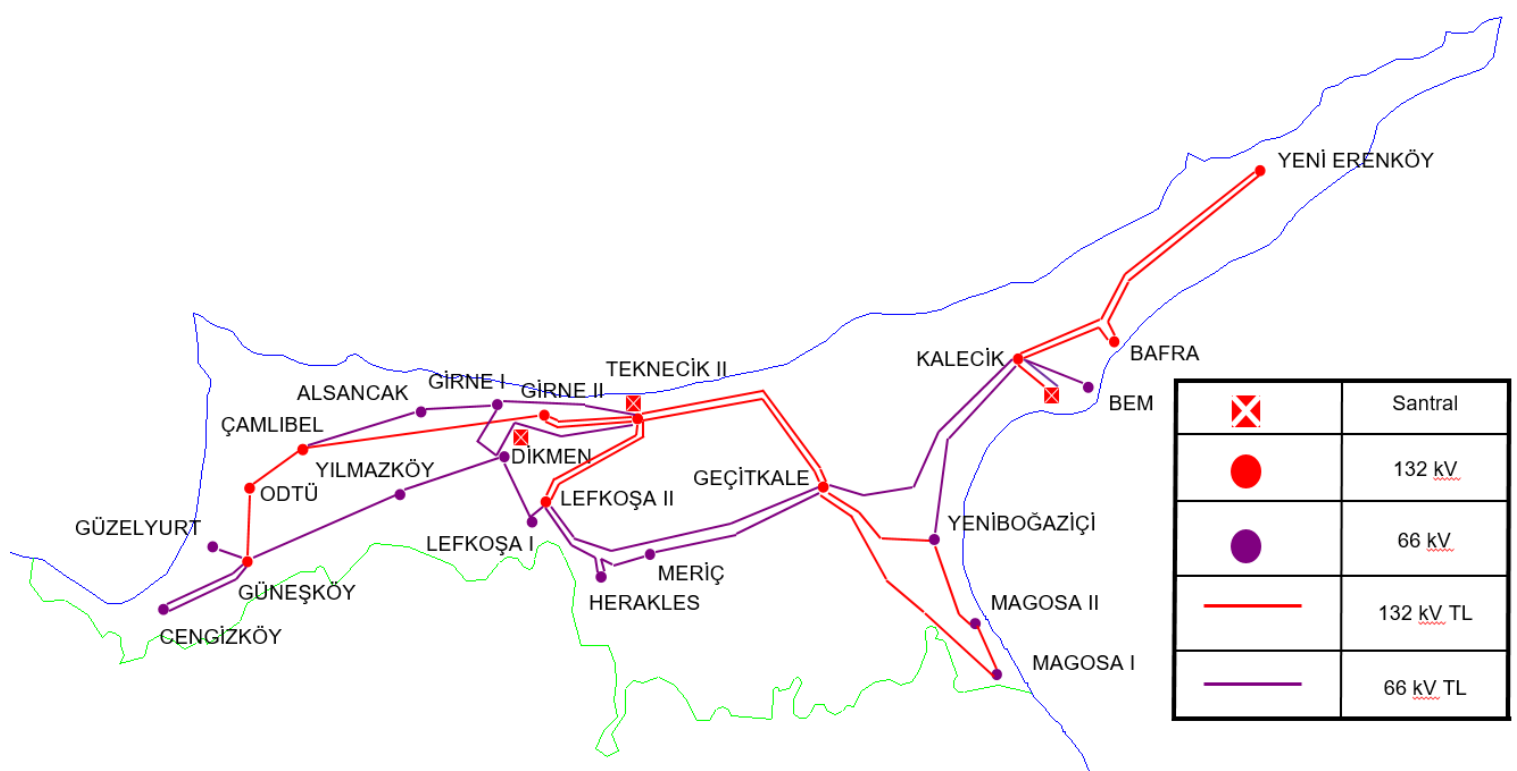

Figure 1. North Cyprus Island Grid Network 


\section{HVDC TRANSMISSION TECHNOLOGIES}

With the development of the AC system by Nikola Tesla and the transformer, the AC system became more attractive for transporting energy. [13] These developments in the mid-1890s caused the power system to be built in AC. DC did not play any significant role for the first 60 years of power transmission until the early 1950s; mercury valves were developed, which allowed a high voltage DC (HVDC) transmission system to be used $[14,15]$.

In the spring of 1970, the first thyristor-based HVDC transmission link went into operation, connecting the island of Gotland with the mainland of Sweden [16]. This HVDC converter technology is called line commutated converter (LCC).

With the further development of other semiconductor elements such as insulated gate bipolar transistors (IGBTs), ABB established in 1996 the first VSC-HVDC link on the island of Gotland and started a new era for HVDC transmission. This technology is very suitable to connect renewable energy sources and other reasons; therefore, much research has been committed.

The HVDC technologies can be classified into two categories based on their terminal voltage and current waveforms at their DC side, the LCC and the VSC. The LCC keeps the DC current at the same polarity, and therefore the direction of the power flow through the converter is determined by the polarity of the DC voltage. The LCC generates voltage and current harmonics on the AC side [17]. Today with LCC power ratings up to $10000 \mathrm{MW}$ with a DC voltage of $\pm 1100 \mathrm{kV}$ and a transmission distance of more than $3000 \mathrm{~km}$ are possible [18].

On the contrary, the VSC keeps the DC voltage at the same polarity, and the polarity of the DC current determines the direction of the power flow. These converters are built with fully controllable switches such as IGBTs. These switches can conduct and interrupt the current at any instant by a gating command [17, 19]. Nowadays, VSC-HVDC links of up to $2600 \mathrm{MW}$ with a DC voltage of up to $\pm 525 \mathrm{kV}$ and a transmission distance of more than $1500 \mathrm{~km}$ are possible [18].

HVDC applications are used in many places today, but five main areas can be listed as follows: [20]

1) Long Distance Bulk Power Transmission; Because of lower operating costs and efficiency, dc transmission is more economical after some distances than ac transmission.

2) Cable Transmission; No limitations on dc cable length compared to ac, which creates different opportunities for interconnected transmission. For distant cases, dc transmission is preferred.

3) Asynchronous Ties; In ac transmission, a standard frequency needs to be used so power flow possible between networks. With DC connection, this requirement disappears, so connecting asynchronous grids becomes possible.

4) Offshore Transmission; Because of sudden load changes in offshore platforms, frequency problems can occur. With non-frequency dependence of dc transmission, controlling these situations becomes easier. For example, big offshore wind farms use this technology to make transmission efficient and provide reactive support.

5) Power Delivery to Large Urban Areas; With HVDC technology, energy transmission is possible for the areas without the local generation. After specific distances, this method is more economical than traditional transmissions.

Based on the connection method, there are multiple topologies. These include monopole, bipolar, and back-to-back connections mainly. Fig. 2 shows the basic schematic topologies [20]. 


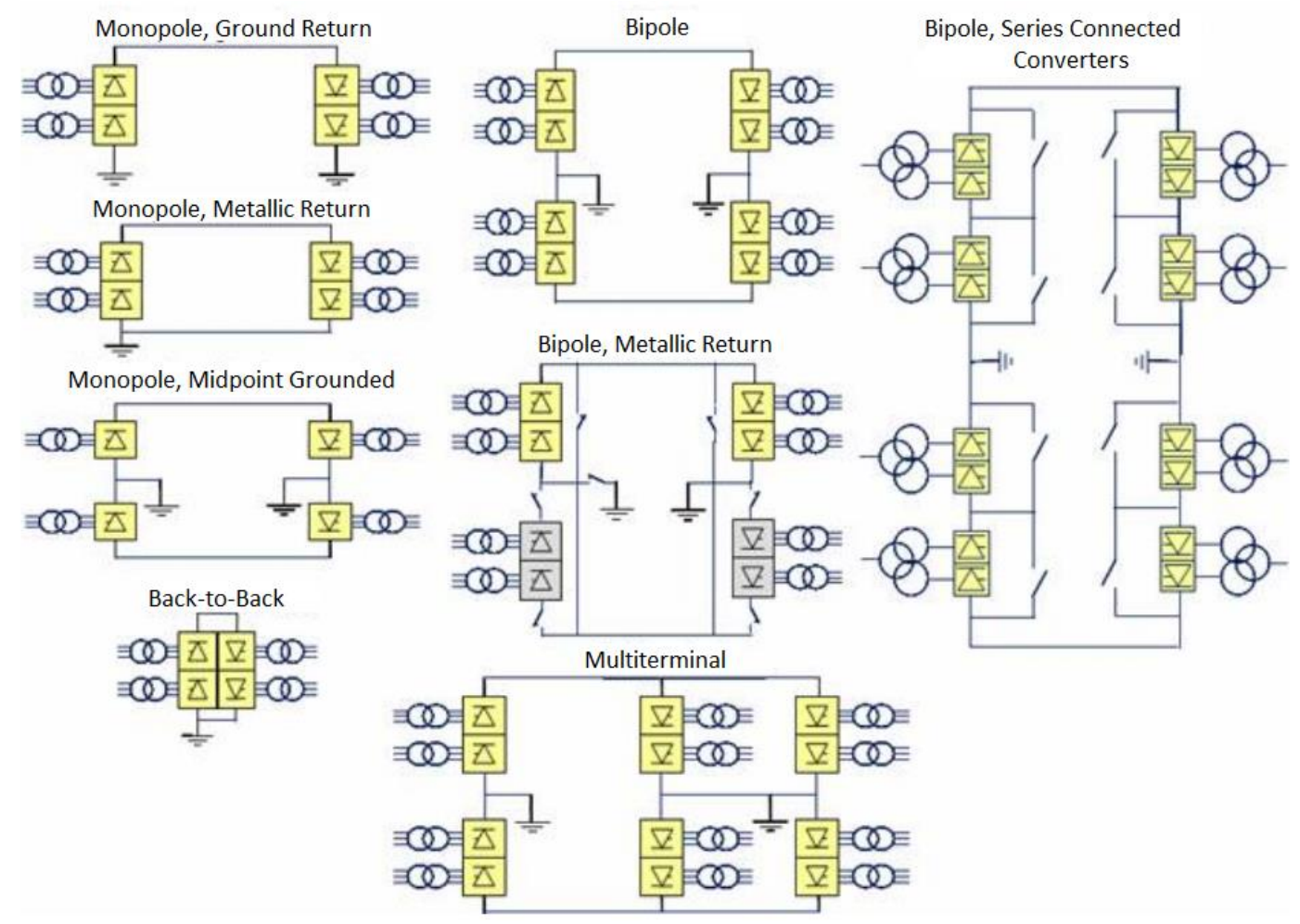

Figure 2. HVDC Connection Topologies

\section{Possible Advantages and Disadvantages of HVDC Connection}

The North Cyprus and Turkey HVDC transmission system offer many advantages, which can be grouped as technological advantages of HVDC and the advantages regarding the North Cyprus and Turkey case. First, the technological advantages of HVDC compared to HVAC will be discussed, and a comparison between LCC and VSC HVDC technologies will be made. Then, the advantages of North Cyprus and Turkey HVDC transmission will be examined.

While more detailed and parametric comparisons can be made, we can show the main technological advantages of HVDC over HVAC as follows; [21]

a) More control over power

b) No limit on cable length (Less interference to telecommunication lines also)

c) Asynchronous transmission is possible between networks.

d) Less loss on transmission lines (Less corona effect)

While these hold excellent ground, HVDC has some disadvantages compared to HVAC;

a) More complicated and expensive conversion stations

b) Design and operation on multi-terminal HVDC are sophisticated.

c) Design of circuit breakers for HVDC is complex.

When a comparison is made in economical aspect, HVDC shows promise compared to the HVAC connection. A research-done on HVDC and HVAC costs shows that there is a break-even distance 
of when comparing these two technologies. [22] Fig. 3 shows the change in cost based on transmission distance. Another research calculates this breakeven distance is $80 \mathrm{~km}$ for underwater transmission. [23]. These research shows that while different conditions can have different costs similar distances can be assumed as break even distance for HVDC.

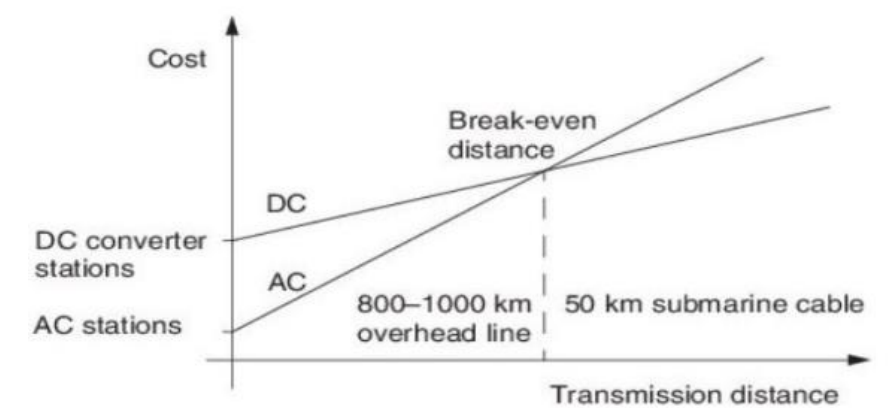

Figure 3. Cost vs Transmission Distance for DC and AC Transmission [22]

Besides technical comparisons, there are case-based advantages and disadvantages, like in this case for North Cyprus and Turkey transmission. For North Cyprus and Turkey connection, advantages are as follows;

a) North Cyprus is in a very strategic position in the Mediterranean Sea, so maintaining reliable energy on the island is vital for North Cyprus and Turkey.

b) To complete the Mediterranean grid circle under discussion is more feasible than a possible connection between South Cyprus and Greece, as shown in Fig. 4.

c) This transmission line will make the North Cyprus network grid very reliable, which will increase renewable generation drastically for both North Cyprus and South Cyprus. This increase in renewable generation would reduce carbon emissions. [1]

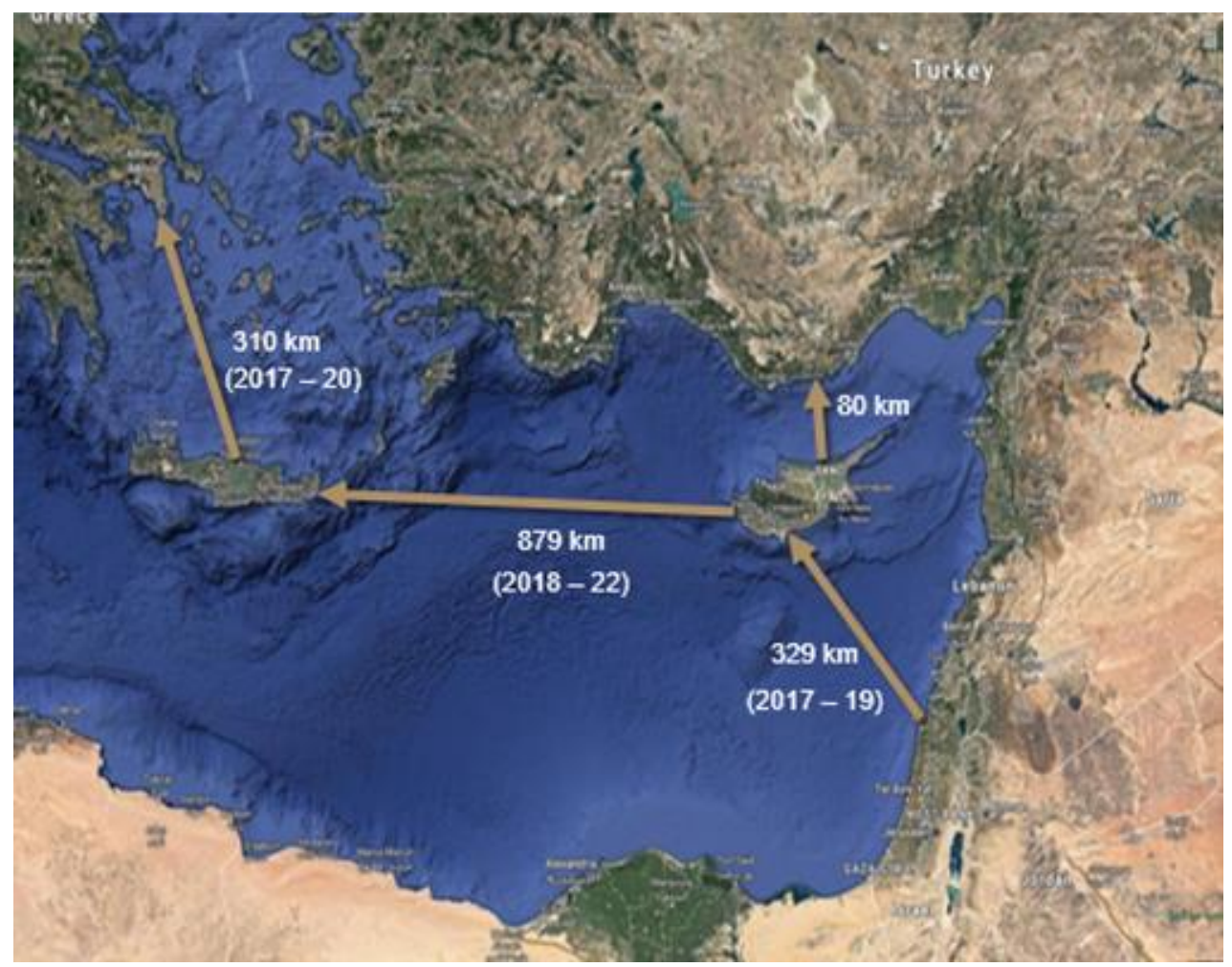

Figure 4. EuroAsia Interconnector 


\section{THEORY, METHODOLOGY AND AVAILABLE DATA}

\section{Optimal Power Flow}

Optimal Power Flow (OPF) is an optimization method that combines economic dispatch equations with power flow equations. It can be done for multiple purposes like minimizing the cost, reducing load shedding, or decreasing losses. To complete the optimization problem, OPF considers equality and inequality constraints. These include real and reactive power balances, generator voltages, MW interchanges, and multiple limits like generation limits and line limits. There are multiple research conducted for power flow calculations which consists HVDC technologies. [24-26] For an economic analysis of HVDC between Turkey and North Cyprus, we used MATPOWER's own Optimal Power Flow algorithm with North Cyprus Grid Model and generator cost function results obtained accordingly.

The MATPOWER AC OPF algorithm aims to optimize generator cost functions based on real and reactive power injections for each generator. The standard version of Optimal Power Flow can be summarized as;

$$
\min _{x} f(x)
$$

Subject to

$$
\begin{gathered}
g(x)=0 \\
h(x) \leq 0 \\
x_{\min } \leq x \leq x_{\max }
\end{gathered}
$$

Where objection function Eq. (1) is the summation of cost functions of real and reactive power injections, optimization variable $\mathrm{x}$ is defined as a matrix where voltage angle, magnitude, real power, and reactive power for each node (node) and generator follows. Equality constraints Eq. (2) consists of nodal power balance equations where voltage angle and magnitude are used with real and reactive power. Inequality constraints Eq. (3) consists of branch flow limits based on voltage angle and magnitude. The variable limits Eq. (4) include reference node angle and voltage upper and lower limits for all node voltage magnitude and real and reactive generator injections. Detailed explanations for optimal power flow used in this study can be found in [11].

This analysis method is used to determine the utilization of transmission lines between the island and the mainland. Based on utilization, cost analysis is done, and price differences are estimated.

\section{Available Data}

\section{North Cyprus Electricity Grid MATPOWER Model and Characteristics}

North Cyprus's high voltage electric grid model is used for this analysis. Detailed North Cyprus's grid was modeled based on the data provided by island National Electricity Company, KIB-TEK, using DigSilent Power Factory software. This model is separated based on regions on the island and consists of 33 nodes, which includes one extra node for the HVDC connection point. The island's general load is $289.5 \mathrm{MW}$, and the non-renewable generation capacity besides the HVDC connection is 404 MW. The prepared model is illustrated in Fig. 5. 


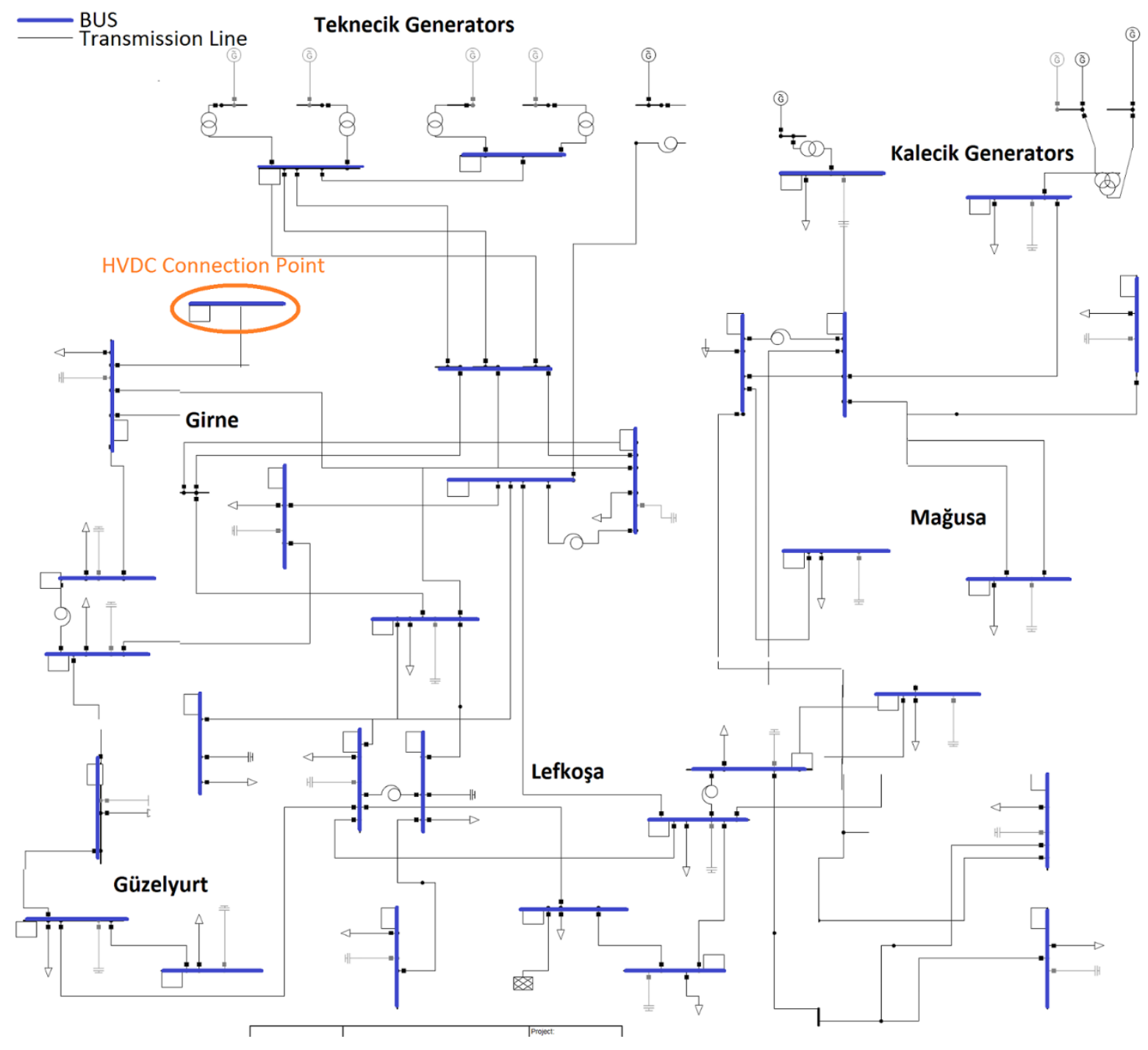

Figure 5. TRNC Grid Model

\section{North Cyprus Monthly Electricity Generation}

Like many Mediterranean islands, North Cyprus has seasonal characteristics. Rising temperatures in the summer months lead to high air conditioning use. This usage can be seen in electricity generation numbers as they increase. Synchronous generation methods in North Cyprus all use Fuel Oil No. 6. The national electric company, KIB-TEK, does not share the specific type of fuel oil information, so the average price for Heavy Fuel Oil is used in the analysis. Table 1 shows the generation capacity and characteristics of North Cyprus provided by KIB-TEK [27].

Table 1. Generation Capacities of North Cyprus [28]

\begin{tabular}{cccccccc}
$\begin{array}{c}\text { Technology } \\
\text { of } \\
\text { Generation }\end{array}$ & $\begin{array}{c}\text { Nominal } \\
\text { Capacity } \\
{[\mathrm{MW}]}\end{array}$ & $\begin{array}{c}\text { Internal } \\
\text { Consumption } \\
{[\mathrm{MW}]}\end{array}$ & $\begin{array}{c}\text { Fuel Rate } \\
[\mathrm{kg} / \mathrm{M}] \mathrm{Wh}]\end{array}$ & $\begin{array}{c}\text { Fossil } \\
\text { Fuel } \\
\text { Type }\end{array}$ & $\begin{array}{c}\text { Avg } \\
\text { Marginal } \\
\text { Cost }\end{array}$ & $\begin{array}{c}\text { Lowest } \\
\text { Marginal } \\
\text { Cost }\end{array}$ & $\begin{array}{c}\text { Highest } \\
\text { Marginal } \\
\text { Cost }\end{array}$ \\
\hline Teknecik & 120 & 5 & 270 & HFO & 118,125 & 67,5 & 168,75 \\
Teknecik & 120 & 5 & 270 & HFO & 118,125 & 67,5 & 168,75 \\
Teknecik & 140 & 5 & 180 & HFO & 78,3 & 44,74 & 111,86 \\
Kalecik & 140 & 5 & 180 & HFO & 78,3 & 44,74 & 111,86 \\
\hline
\end{tabular}


Fuel data obtained from a case study for Malta. Malta and North Cyprus island networks have similar configurations, so the data used should result in this HVDC research. Fuel data taken from [29] can be found in Table 2 .

Table 2. Used Oil Prices [30]

\begin{tabular}{lcc}
\hline & Fuel Price $[€ / \mathrm{kg}]$ & {$[€ / \mathrm{MWh}]$} \\
\hline Base (Avg) Oil Price & 0.42 & 35 \\
Low Oil Price & 0.24 & 20 \\
High Oil Price & 0.6 & 50 \\
\hline
\end{tabular}

Table 3 has monthly electricity generation given in [27] based on generators owned by KIB-TEK.

Table 3. Monthly Electricity Generation in 2019 [MWh]

\begin{tabular}{lllll}
\hline Month & Teknecik Steam 1 & Teknecik Steam 2 & Teknecik Diesel & Kalecik Diesel \\
\hline 1 & 27255 & 27930 & 59065 & 42597 \\
2 & 20796 & 18150 & 59005 & 28755 \\
3 & 0 & 21053 & 59425 & 47040 \\
4 & 0 & 4124 & 59459 & 47407 \\
5 & 0 & 3668 & 59676 & 57024 \\
6 & 8735 & 26830 & 59929 & 47520 \\
7 & 29180 & 29798 & 60135 & 52180 \\
8 & 21493 & 29602 & 64259 & 60526 \\
9 & 24538 & 24058 & 59950 & 42247 \\
10 & 21940 & 0 & 59666 & 45334 \\
11 & 0 & 15020 & 59886 & 35506 \\
12 & 13929 & 27235 & 39386 & 58710 \\
TOTAL & 153937 & 200233 & 660455 & 506136 \\
\hline
\end{tabular}

\section{Turkey-North Cyprus Connection Characteristics}

While no interconnector exists between the two countries, it is assumed to be built eventually. The plan for this connector is to start with a $200 \mathrm{MW}$ connection and increase its capacity with time. Table 4 shows the cost calculations when the undersea cable is assumed to be $95 \mathrm{~km}$ with $10 \mathrm{~km}$ of an overhead line. The calculation is based on Edwaren Liun's research. [29].

Table 4. Interconnector Estimated Cost [30]

\begin{tabular}{cccc}
\hline \multicolumn{2}{c}{ Assumptions } & \multicolumn{2}{c}{ Calculations } \\
\hline$L_{O H}$ & $10 \mathrm{~km}$ & $C_{O H}$ & 13.12 Million \$ \\
$L_{S C}$ & $95 \mathrm{~km}$ & $C_{S C}$ & 156.55 Million \$ \\
$P$ & $200 \mathrm{MW}$ & $C_{C}$ & 187.77 Million \$ \\
\hline \multicolumn{3}{r}{ Total } & 357.44 Million \$ \\
\hline
\end{tabular}

\section{Turkish Electricity Market Spot Prices}

Because of the established electricity market in Turkey, data for spot market prices can be found easily. In this research, we used monthly average prices in the year 2019. We assumed North Cyprus would be a customer on the spot market, and its role will not affect prices in Turkey. For research purposes, the HVDC connection and the generators are always assumed to be available. Because KIB-TEK shared 11 months of generation data, only 11-month spot prices were obtained. Monthly spot prices can be found in Fig. 6. 


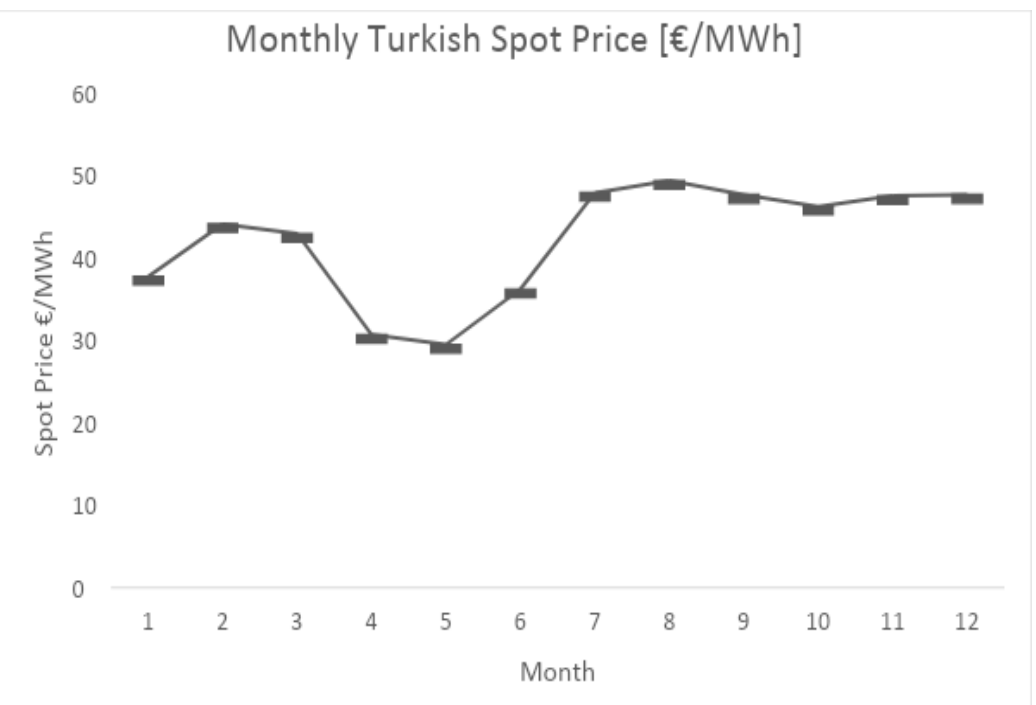

Figure 6. Monthly Spot Prices on Turkish Electricity Market [30]

\section{RESULTS AND DISCUSSION}

\section{OPF Analysis Results}

OPF is done based on generation prices and spot prices given in the previous sections. HVDC interconnector to the North Cyprus grid is added based on the method explained in MATPOWER manual, which is described as adding another generator. Since the analysis is done on a static basis, the two methods only differ in price at first. The connection point for interconnection to the grid is selected with normal power flow calculations done on multiple possible nodes. These nodes include Alsancak, Girne HV, Teknecik. The best result with fewer losses came with the Girne HV node connection, so the OPF calculations were done assuming that the interconnection was made via Girne HV node. System summaries with and without the HVDC interconnector cases can be found in Table 5 .

Table 5. System Summary of North Cyprus Grid

\begin{tabular}{lcc}
\hline & Without HVDC interconnector & With HVDC interconnector \\
\hline Total Gen. Capacity (MW) & 404 & 604 \\
Total Load (MW) & 289 & 289 \\
Losses (MW) & 5,86 & 3,26 \\
Nodes & 32 & 33 \\
Generators & 5 & 6 \\
Lambda P \$MWh & 95,98 & 88,40 \\
HVDC Utilization (MW) & - & $200 \mathrm{MW}(100 \%)$ \\
\hline
\end{tabular}

It can be clearly seen that Lambda P decreases nearly $10 \%$ for the maximum value of a node. Also, system loss decreases with interconnector nearly by half compared to the without HVDC interconnector case. This decrease can be interpreted as an improvement in the system performance, and general electricity costs get lower with HVDC, so establishing a transmission line is a logical selection compared to another diesel generator.

\section{Monthly Cost Calculation}

After the basic analysis was conducted on available data given in the previous sections, monthly generation costs were calculated. Results for both cases with and without HVDC can be found in Fig. 7. 


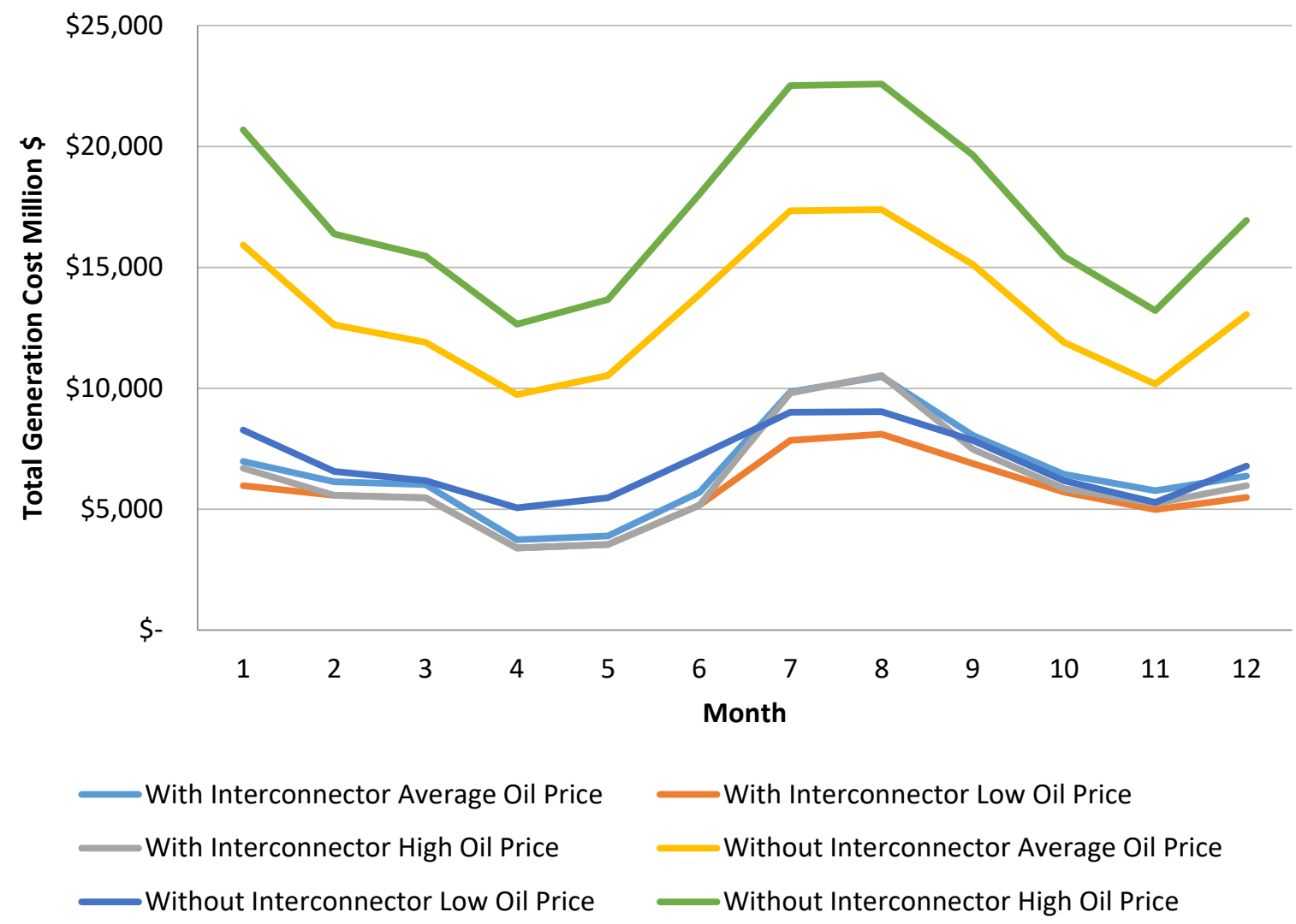

Figure 7. Estimated Monthly Generation Costs of Electricity

Based on the values found with a simple calculation, a $28 \%$ to $72 \%$ decrease can be observed based on oil price on a specific period. This dependency makes the North Cyprus grid very volatile against oil prices. While this calculation is fundamental and requires further research for more accurate results, we can say that a very considerable generation cost reduction can be achieved.

Also, this analysis is done based on static spot prices for North Cyprus. If established, North Cyprus can be a clear player in the Turkish Electricity Market and get cheaper energy. Further research can be done to calculate the payback period of HVDC connection and carbon dioxide emission reduction by increasing renewable energy generation.

\section{CONCLUSION}

This paper focuses on the current energy situation in Turkey and North Cyprus, the technology of an HVDC interconnection and economic analysis of a transmission line between Turkey and North Cyprus.

Turkey now has the second-biggest electrical grid and has a connection to Europe. North Cyprus has a sensitive and small electrical grid and wants to increase its electricity generation capacity. A capacity increase will allow more renewables and cheaper energy for the island. Having a transmission line between two countries and using HVDC VSC technology for this transmission is suggested. In addition, this kind of project can pave the way for an electricity market for North Cyprus. 
The paper aims to help projects regarding HVDC transmission and possible transmission lines between island networks and mainland grids. Engineers, investors, or other stakeholders can use this research in evaluating similar projects.

For the case considered in this research, facts show that the two countries require this connection, and benefits like increased renewable energy indirectly help for a better future. When we look at essential cost estimation, optimal power flow, and fundamental generation cost analysis, this project looks feasible compared to other similar HVDC transmission line projects.

\section{REFERENCES}

[1] Direl K. Northern Cyprus Power Grid and the effects of Renewable Energy. In: EEMKON Elektrik Elektronik Mühendisliği Kongresi; 14-16 November 2019: EMO Publish, pp. 1-14.

[2] Suri M. Global Solar Atlas 2.0 Technical Report. Washington, DC: World Bank, 2019

[3] Ozerdem O.C, Biricik., S. Overview of energy system and major power quality problems in north Cyprus, Technical and Physical Problems of Engineering, 2011 pp. 71-75.

[4] Wang J, Zong Y, You S, Traeholt C. A review of Danish integrated multi-energy system flexiblity options for high wind power penetration. Clean Energy, 2017; I:1-13, DOI: 10.1093/ce/zkx002

[5] Zafeiratou E, Spataru C. Long Term analysis of submarine transmission grid extensions between the Greek islands and the mainland. In: International Conference on Smart Energy Systems and Technologies (SEST); 9-11 September 2019: IEEE, Porto, Portugal, pp. 1-6.

[6] Georgiou, P, Mavrotas, G, Diakoulaki, D. The effect of islands' interconnection to the mainland system on the development of renewable energy sources in the Greek power sector. Renewable and Sustainable Energy Reviews 15. 2011. pp. 2607-2620. DOI: 10.1016/j.rser.2011.03.007

[7] Nanou S, Papadapulos M, Papathanassiou S. Assessment of Island Interconnection Projects via HVDC Links of partial capacity: The case of Crete. In: Cigre Paris Session; 22-26 August 2016: CIGRE, Paris, pp. 1-9.

[8] Papadopoulos M, Boulaxis N, Tsili M, Papathanassiou S. Increased Wind Energy Exploitation Via Interconnection Of Aegean Islands To The Mainland Grid. In: 19th International Conference on Electricity Distribution; 21-24 May 2007: Vienna, pp.1-4.

[9] Mosca C, Bompard E, Aluisio B, Migliori M, Vergine C, Cuccia P. HVDC for frequency stability under RES penetration: the Sardinia Island case. In: 2019 AEIT HVDC International Conference (AEIT HVDC), 9-10 May 2019: IEEE, pp. 1-6.

[10] Papadopoulos M, Boulaxis N, Tsili M, Papathanassiou S. Interconnection of the Cycladic Islands to the Mainland Grid. In: 5th WSEAS Int. Conf. on Power Systems and Electromagnetic Compatibility; 23-25 August 2005: Corfu Greece, pp. 429-435.

[11] Zimmerman R, Murillo-Sánchez C. MATPOWER User's Manual (Version 7.1). Zenodo, 2019. DOI:10.5281/zenodo.4074122

[12] Internet Web-Site: www.kibtek.com/uretim, KIB-TEK TRNC Electricity Generation Stations, 2015, 10 June 2020.

[13] Kundur P. Power System Stability and Control. New York, USA: McGraw-Hill, 1994.

[14] Fairley P. DC Versus AC: The Second War of Currents Has Already Begun. In: IEEE Power and Energy Magazine 2012, I:10-6, pp. 104-103. DOI: 10.1109/MPE.2012.2212617

[15] Asplund G, Lennart C, Tollerz O, 50 years - Part 1 ABB - from pioneer to world leader. In: ABB Review, 2003 pp. 6-8.

[16] Anonymous. 50 years HVDC - Part II The semiconductor 'takeover'. In: ABB Review, 2003. pp. 10-13.

[17] Imhof, M. C. V. Voltage Source Converter Based HVDC - Modelling and Coordinated Control to Enhance Power System Stability. PhD, ETH Zurich, Zurich, Sweden, 2015.

[18] Internet Web-Site: http://www.abb.ch/cawp/seitp202/3a8302e9925218a4c1257d3f00451b52.aspx, Bewa $\mathrm{H}$. ABB develops complete system solution for 1,100 kV HVDC power transmission, 2014

[19] Yazdani A, Iravani R. Voltage-Sourced Converters in Power Systems - Modeling, Control, and Applications. Hoboken, NJ, USA: John Wiley \& Sons, Inc., 2010.

[20] Bahrman M. HVDC Transmission Overview. In: 2008 IEEE/PES Transmission and Distribution Conference and Exposition; 21-24 April 2008: IEEE, pp. 1-7, DOI: 10.1109/TDC.2008.4517304

[21] Ruderwall R, Charpentier J, Sharma R. High Voltage Direct Current (HVDC) Transmission Systems Technology Review. In: Energy Week 2000, 7-8 March 2000: Washington, pp. 1-17. 
[22] Jahan M, Hamim S, Imran M, Abeadin M, Chowdhury M Comparative cost analysis of VSC-HVDC and HVAC as transmission system for a $50 \mathrm{MW}$ offshore wind farm in Hatiya Island. In: 2020 2nd International Conference on Sustainable Technologies for Industry 4.0 (STI);19-20 December 2020; pp.14.

[23] Pillay C, Kabeya M, Davidson I. Transmission Systems: HVAC vs HVDC In: Proceedings of the 5th NA International Conference on Industrial Engineering and Operations Management; 10 - 14 August 2020: pp. 2061-2077

[24] Wu L, Fan X, Xu M, Li Z, Wang X, Zhang X, Jin H. Research and application of a power-flow-calculation method in multiterminal VSC-HVDC power grid. Global Energy Interconnection, 2019; 1: 37-44, DOI: 10.1016/j.gloei.2019.06.005

[25] Wiget R, Andersson G. DC optimal power flow including HVDC grids, In:2013 IEEE Electrical Power \& Energy Conference, 21-23 August 2013:IEEE, pp. 1-6.

[26] Feng W, Tuan A, Tjernberg L, Mannikoff A, Bergman A. A New Approach for Benefit Evaluation of Multiterminal VSC-HVDC Using A Proposed Mixed AC/DC Optimal Power Flow. IEEE Transactions on Power Delivery 2014, I:29, pp. 432-443. DOI:10.1109/TPWRD.2013.2267056

[27] Internet Web-Site: www.kibtek.com/wp-content/uploads/Statistikler/2019_statistic.pdf, TRNC Total Generation and Usage of Electricity in 2019, 1 Jan 2020

[28] Ries J, Gaudard L, Romerio F. Interconnecting an isolated electricity system to the European market: The case of Malta. Utilities Policy 2016; I: 1-14, DOI: 10.1016/j.jup.2016.03.001

[29] Liun E. Suparman. Cost estimation of HVDC transmission system of Bangka's NPP candidates. 4th International Conference on Advances In Nuclear Science And Engineering; 16-19 September 2013: AIP Publishing, Bali, pp. 162-166.

[30] Internet Web-Site: rapor.epias.com.tr/rapor/xhtml/ptfSmfListeleme.xhtml, EPİAŞ Report of Costs, 10 Jun 2020 